\title{
Carbon dioxide de-airing in minimal invasive cardiac surgery, a new effective device
}

\author{
Jesper Nyman ${ }^{1,2^{*}}$, Peter Svenarud ${ }^{2,3}$ and Jan van der Linden ${ }^{1,2}$
}

\begin{abstract}
Background: Arterial air embolism during open heart surgery may cause postoperative complications including cerebral injury, myocardial dysfunction, and dysrhythmias. Despite standard de-airing techniques during surgery large amounts of arterial air emboli may still occur, especially during weaning from cardiopulmonary bypass. To prevent this insufflation of carbon dioxide in the wound cavity has been used since the 1950s. The aim of this study was to assess a new mini-diffuser for efficient carbon dioxide de-airing of a minimal invasive cardiothoracic wound cavity model. Up until now no device has been evaluated for this purpose.
\end{abstract}

Methods: A new insufflation device, a mini-diffuser, was tested. A thin plastic tube was used as control. The end of the mini-diffuser or the control, respectively, was positioned in a minimal invasive thoracic wound model. Remaining air content was measured during steady state and during intermittent suction with a rough suction device at different carbon dioxide flow rates. Measurements were also carried out in the open surgical wound during minimal invasive aortic surgery in six patients.

Results: The air content was below $1 \% 4 \mathrm{~cm}$ below the surface of the open wound model during continuous carbon dioxide inflow of $2-10 \mathrm{~L} / \mathrm{min}$ with the mini diffuser. In comparison, carbon dioxide insufflation via the openended tube resulted in a mean air content between 10 and 75\%. The mean air content of the wound model remained below $1 \%$ at a carbon dioxide flow rate of $3-5 \mathrm{~L} / \mathrm{min}$ during intermittent application of a suction device with a suction rate of $15 \mathrm{~L} / \mathrm{min}$. In 6 patients undergoing minimal invasive aortic valve replacement air content in the open surgical wound remained below $1 \%$ at a continuous carbon dioxide flow rate of 5 and $8 \mathrm{~L} / \mathrm{min}$ via the mini-diffuser, respectively.

Conclusions: The mini diffuser was effective for carbon dioxide de-airing, i.e. $<1 \%$ remaining air, of a minimal invasive cardiothoracic wound cavity model with and without intermittent rough suction as well as in patients undergoing minimal invasive aortic valve surgery.

Keywords: Carbon dioxide, Minimal invasive cardiac surgery, de-airing, Emboli

\section{Background}

Arterial air embolism during open heart surgery may cause postoperative complications including cerebral injury, myocardial dysfunction, and dysrhythmias [1-7]. Despite standard de-airing techniques during surgery

\footnotetext{
* Correspondence: jesper.nyman@sll.se

${ }^{1}$ Division of Perioperative Medicine and Intensive Care, Section

Cardiothoracic Surgery and Anesthesiology, Karolinska University Hospital

Solna, SE-17176 Stockholm, Sweden

${ }^{2}$ Department of Molecular Medicine and Surgery, Karolinska Institutet,

Stockholm, Sweden

Full list of author information is available at the end of the article
}

large amounts of arterial air emboli may still occur, especially during weaning from cardiopulmonary bypass $[8$, 9]. To prevent this, insufflation of carbon dioxide $\left(\mathrm{CO}_{2}\right)$ in the wound cavity has been used since the 1950s. As $\mathrm{CO}_{2}$ is $>25$ times [10] more soluble than air in blood at $37-38^{\circ} \mathrm{C}$, arterial $\mathrm{CO}_{2}$-emboli are much better tolerated than air emboli $[2-5,11,12]$. Furthermore, $\mathrm{CO}_{2}$ has a $50 \%$ higher density than air and will hence displace air by gravity in the open wound cavity.

The use of $\mathrm{CO}_{2}$ in minimal invasive cardiac surgery is probably more important compared with open cardiac 
surgery, as minimal invasive cardiac surgery does not permit normal de-airing maneuvers. Furthermore, the minimal invasive surgical wound cavity is much smaller, which necessitates a much smaller administration device for $\mathrm{CO}_{2}$ delivery. So far no device has been evaluated for this purpose.

The aim of this study was to assess a new device, a mini-diffuser, for efficient $\mathrm{CO}_{2}$ de-airing of a minimal invasive cardiothoracic wound cavity model and in patients undergoing minimal invasive aortic valve surgery.

\section{Materials and methods}

\section{Insufflation devices and experimental wound model}

A disposable insufflation device, the $\mathrm{CO}_{2}$-diffuser (CarbonMini $^{\circ}$ Cardia Innovation AB, Stockholm, Sweden) consists of a $2 \mathrm{~m}$ long PVC tube with inner diameter $1 / 4$ inch $(6.35 \mathrm{~mm})$, a bacterial filter $(\mathrm{ORO} 1 \mathrm{H}$ from Pall Medical, Portsmouth, U.K.), a $0.20 \mathrm{~m}$ PVC tube with inner diameter $1 \mathrm{~mm}$ inside which a metal thread runs, and a soft polyurethane cylindrical diffuser with a diameter of $7 \mathrm{~mm}$ and a length of $17 \mathrm{~mm}$, giving a surface area of $374 \mathrm{~mm}^{2}$ (Fig. 1). A plastic tube with an inner diameter of $1 \mathrm{~mm}$ was used as control, as this is a frequently used device to insufflate $\mathrm{CO}_{2}$ in wound cavities in minimal invasive cardiac surgery.

The size of the minimal invasive cardiothoracic wound model was based on measurements (median) of the minimal invasive cardiothoracic wound cavities of three patients undergoing minimal invasive cardiac surgery through a partial sternotomy. The opening of the wound model was $70 \mathrm{~mm}$ in diameter and it had a depth of 44 $\mathrm{mm}$. Furthermore, a simplified aortic model with a size of $50 \times 40 \times 40 \mathrm{~mm}$ was positioned at its base.

\section{Instrumentation}

The $\mathrm{CO}_{2}$ gas flow was measured with a back-pressure compensated $\mathrm{O}_{2}$-flowmeter, as $\mathrm{CO}_{2}$-flowmeters are rarely used in clinical practice. The $\mathrm{O}_{2}$-reading scale was

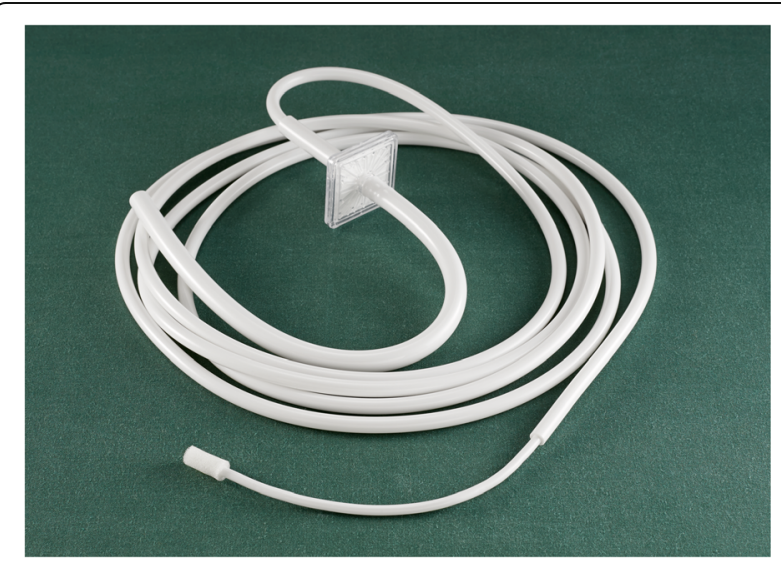

Fig. 1 Photo of the mini-diffuser adjusted for $\mathrm{CO}_{2}$ by a universal flowmeter (ABB/Fisher \& Porter, Göttingen, Germany), because of the higher density of $\mathrm{CO}_{2}$ gas. The universal flowmeter consisted of a measuring tube (FP $1 / 1 / 4-16$ G-5/81) with a spherical stainless steel float (SS-14). However, the universal flowmeter was not used for direct measurements in the study, due to its lack of compensation for back-pressure. This problem was avoided during the calibration by measuring the $\mathrm{CO}_{2}$ outflow distal to the end of the insufflation devices. The tube reading scale of the universal flowmeter was calculated for the used gas (medical $\mathrm{CO}_{2}$, AGA Gas AB, Stockholm, Sweden) at 20 degrees $C$ and at 1013 mbar with a computer program (FlowSelect version 2.0, ABB/Fisher \& Porter, Göttingen, Germany). Coronary suction was not used at the time of measurement. The suction effect of the rough suction was 5,10 , and $15 \mathrm{~L} / \mathrm{min}$, controlled by a flowmeter.

The air displacement was analyzed by assessing the air content inside the model. The air content was measured by continuous sampling of the oxygen $\left(\mathrm{O}_{2}\right)$ content given by the formula:

$$
\operatorname{air} \%=\frac{O_{2} \%}{O_{2}(\text { ref. }) \%} \cdot 100
$$

where $\mathrm{O}_{2}$ (ref.) $\%=21 \%$ (14) which is the normal $\mathrm{O}_{2}$ content in atmospheric air at sea-level. The $\mathrm{O}_{2}$-content was measured with an $\mathrm{O}_{2}$-sensor (CheckMate 9900, PBI Dansensor, Denmark). This $\mathrm{O}_{2}$-instrument has a sampling volume of $<2 \mathrm{ml}$, a response time of $<2 \mathrm{~s}$, a range of measurement of 0.0001 to $100 \% \mathrm{O}_{2}$, and an accuracy of $1 \%$ of the measured value (the response time of optical infrared $\mathrm{CO}_{2}$-sensors are usually $>10 \mathrm{~s}$ with a fix accuracy of approximately $2 \% \mathrm{CO}_{2}$-units in the range 0 $100 \%)$. The sampling probe was $2.0 \mathrm{~mm}$ thick sterile and disposable pressure monitoring tube (B. Braun, Meisungen, Germany).

\section{Measurements}

The tip of the insufflation device was positioned towards the bottom of the experimental wound cavity at a depth of $25 \mathrm{~mm}$ from the wound surface. $\mathrm{CO}_{2}$ was supplied to the wound cavity via the device at a flow of $2,3,4,5$, and 10 liters per minute $(\mathrm{L} / \mathrm{min})$. The air content was measured during steady state in each quadrant of the wound cavity $15 \mathrm{~mm}$ below the wound area opening and at the base of the wound cavity.

The air displacement efficiency of the new mini-diffuser and the control device for insufflation was assessed during static conditions without suction. The efficiency of the mini-diffuser was thereafter further explored with the addition of the varying degrees of suction, applied via a suction device (Kendall Argyle Yankauer suction tube (fine), Tyco Healthcare, $4.0 \mathrm{~mm}$, Ireland) either for $2 \mathrm{~s}$, 
intermittent suction, or for continuous suction at a depth of $15 \mathrm{~mm}$ from the wound area opening. The $\mathrm{O}_{2}$-content was measured at a depth of $40 \mathrm{~mm}$ at steady state, $60 \mathrm{~s}$ of stable values, before start of intermittent ( $2 \mathrm{~s}$ ) or continuous suction, with 10 measurements during each condition. After start of intermittent suction the $\mathrm{O}_{2}$-content was measured every $5 \mathrm{~s}$ for $25 \mathrm{~s}$. After start of continuous suction the $\mathrm{O}_{2}$-content was measured every $10 \mathrm{~s}$ for $90 \mathrm{~s}$. The remaining $\mathrm{CO}_{2}$ in the model was removed with the help of a rough suction device before every change of $\mathrm{CO}_{2}$ flow rate, insufflation device, or measuring position.

In six patients undergoing minimal invasive aortic valve surgery through a $6 \mathrm{~cm}$ long J-shaped partial sternotomy from the jugulum to the third intercostal space, air content was measured $4 \mathrm{~cm}$ below the wound surface when insufflations the open wound with a mini diffuser, positioned contra-lateral to the measuring site, at a $\mathrm{CO}_{2}$ flow rate of 5 and $8 \mathrm{~L} / \mathrm{min}$, respectively.

\section{Statistics}

Data are presented as mean \pm SD and were analyzed with a commercially available statistic program (SPSS, version 19, IBM). Due to the small numbers, we chose to use nonparametric tests, the Mann-Whitney U-test and the Kruskall-Wallis test, which were applied when appropriate. A $p$-value less than 0.05 was considered significant.

\section{Results}

With the mini-diffuser the air content at $15 \mathrm{~mm}$ depth in the wound model was $0.5 \pm 0.2 \%, 0.5 \pm 0.2 \%, 0.6 \pm$ $0.3 \%, 0.6 \pm 0.3 \%$, and $1.5 \pm 1.2 \%$, respectively, during a continuous $\mathrm{CO}_{2}$ inflow of $2,3,4,5$, and $10 \mathrm{~L} / \mathrm{min}$, respectively. Forty $\mathrm{mm}$ below the surface the corresponding values were $0.8 \pm 0.3 \%, 0.5 \pm 0.2 \%, 0.4 \pm 0.2 \%, 0.3 \pm$ $0.2 \%$, and $0.2 \pm 0.1 \%$, respectively (Fig. 2 ).
When the control device, the open-ended tube, was used to insufflate the wound cavity model, the mean air content was between 10 and $20 \%$ at a $\mathrm{CO}_{2}$ flow of 2 and $3 \mathrm{~L} / \mathrm{min}$, and the mean air content increased to between 20 and $75 \%$ at flow rates of 4,5 and $10 \mathrm{~L} / \mathrm{min}$ (Fig. 3). Thus, the mini-diffuser device de-aired the wound cavity model much more efficiently at all measured flows $(p=$ 0.02) when compared with the control.

Figure 4 depicts the air content when an intermittent rough suction force of $10 \mathrm{~L} / \mathrm{min}$ was applied for two seconds. A very small but significant rise in air content occurred after $5 \mathrm{~s}$ for all flows $(p<0.001)$, after which the air content reversed to steady state levels after $10 \mathrm{~s}$ for all flows. Thus, despite a two second intermittent rough suction force of $10 \mathrm{~L} / \mathrm{min}$ the air content remained below $1 \%$ at all $\mathrm{CO}_{2}$ flow rates, except when the flow was only $2 \mathrm{~L} / \mathrm{min}$, which resulted in an increase of the air content to approximately $2.4 \%(p<0.001)$.

Figure 5 illustrates the air content when an intermittent rough suction force of $15 \mathrm{~L} / \mathrm{min}$ was applied for two seconds. Similarly to what was seen with the addition of a suction rate of $10 \mathrm{~L} / \mathrm{min}$, the mean air content in the model rose significantly after $5 \mathrm{~s}$ at all $\mathrm{CO}_{2}$ flow rates $(p<0.001)$. However, the mean air content only increased above $1 \%$ at a $\mathrm{CO}_{2}$ flow rate of 2 and $10 \mathrm{~L} / \mathrm{min}$. The air content returned to steady state values for all $\mathrm{CO}_{2}$ flow rates already after $10 \mathrm{~s}$, which was similar to the pattern seen when applying a suction rate of $10 \mathrm{~L} /$ min.

The application of a continuous rough suction rate of 5, 10, and $15 \mathrm{~L} / \mathrm{min}$, at $\mathrm{CO}_{2}$ flow rates of $2,3,4,5$, and $10 \mathrm{~L} / \mathrm{min}$, respectively, resulted in a clear pattern. With every increment in $\mathrm{CO}_{2}$ flow rate the air content decreased significantly $(\mathrm{p}<0.001)$ for all three suction rates, except that the air content remained statistically

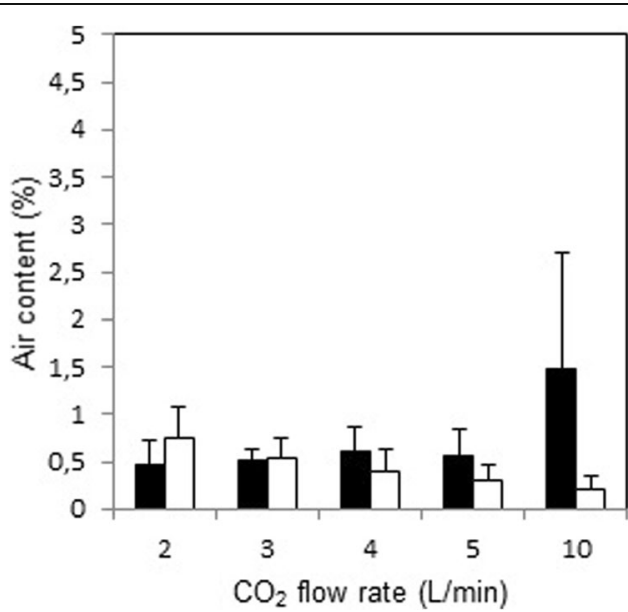

Measuring depth $15 \mathrm{~mm}$

$\square$ Measuring depth $40 \mathrm{~mm}$

Fig. 2 Measured air content at steady state when insufflating $\mathrm{CO}_{2}$ at various flow rates into a minimal invasive cardiothoracic wound cavity model with a new $\mathrm{CO}_{2}$ insufflation device. Air content was measured at a depth of $15 \mathrm{~mm}$ and $40 \mathrm{~mm}$ from the opening surface of the wound cavity model 


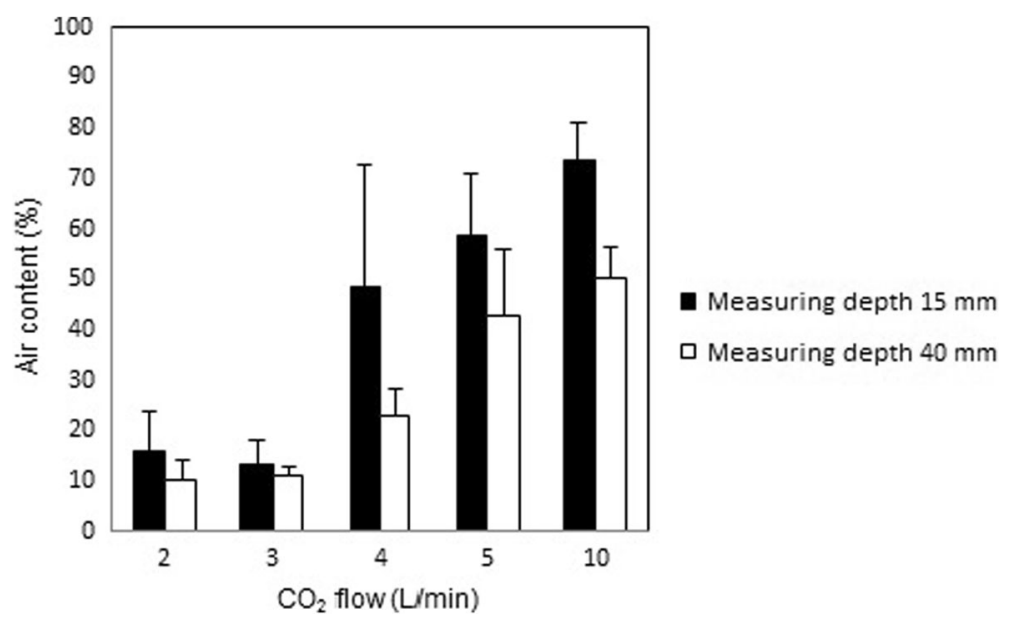

Fig. 3 Measured air content at steady state when insufflating $\mathrm{CO}_{2}$ at various flow rates into a minimal invasive cardiothoracic wound cavity model with an open tube (inner diameter of $1 \mathrm{~mm}$ ). Air content was measured at a depth of $15 \mathrm{~mm}$ and $40 \mathrm{~mm}$ from the opening surface of the wound cavity model

unchanged at a suction rate of $5 \mathrm{~L} / \mathrm{min}$ when the flow rate was increased from 5 to $10 \mathrm{~L} / \mathrm{min}(p=0.21)$. The mean air content was $\leq 10 \%$ at a $\mathrm{CO}_{2}$ flow rate 4,5 , and $10 \mathrm{~L} / \mathrm{min}$, respectively, when applying a continuous rough suction rate of either 5 or $10 \mathrm{~L} / \mathrm{min}$ (Fig. 6). With a $\mathrm{CO}_{2}$ flow rate of $10 \mathrm{~L} / \mathrm{min}$ the air content remained below $10 \%$ for a continuous suction rate of 5,10 , and $15 \mathrm{~L} / \mathrm{min}$.

The mean air content in the open surgical wound of the 6 patients undergoing minimal invasive aortic valve replacement was $0.4 \pm 0.5 \%$ and $0.6 \pm 0.7 \%$ at a continuous $\mathrm{CO}_{2}$ flow rate of 5 and $8 \mathrm{~L} / \mathrm{min}$ via the mini-diffuser, respectively. None of the patients experienced any signs of postoperative deterioration of cerebral or cardiac function (Table 1).

\section{Discussion}

Since many years $\mathrm{CO}_{2}$ is insufflated into the open surgical wound during conventional open cardiac surgery to prevent air embolism. However, studies about a decade ago showed that a conventional administration of $\mathrm{CO}_{2}$ with an open-ended tube caused a high velocity jet into the open surgical wound that created turbulence and thus poor de-airing [13]. Consequently, efficient de-airing could only be achieved by using a device with a diffuser at its end that enables a high gas flow but with a low velocity output [13]. This device, which is used in open cardiac surgery in most countries in the western world (based on information from the manufacturer, Cardia Innovation AB, Stockholm, Sweden), is however by many surgeons considered too large to be utilized in

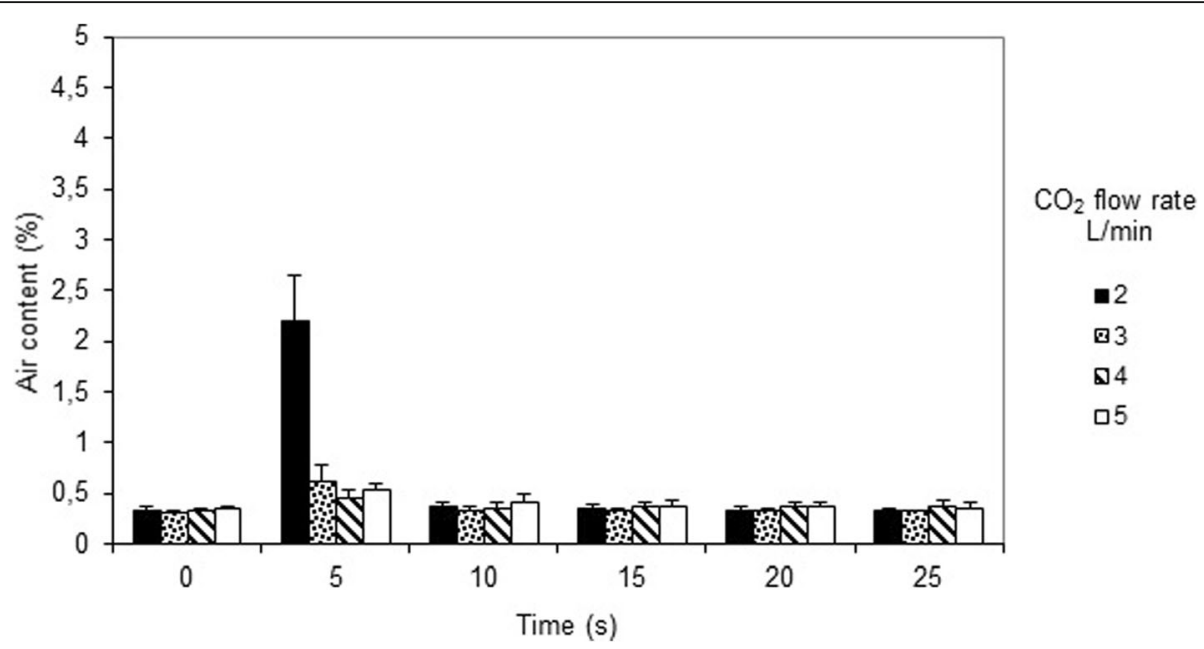

Fig. 4 Air content measured every five seconds, when using the new $\mathrm{CO}_{2}$ insufflation device and intermittent rough suction rate of $10 \mathrm{~L} / \mathrm{min}$ for two seconds from time zero. $\mathrm{CO}_{2}$ was insufflated at a flow rate of $2,3,4$, and $5 \mathrm{~L} / \mathrm{min}$, respectively 


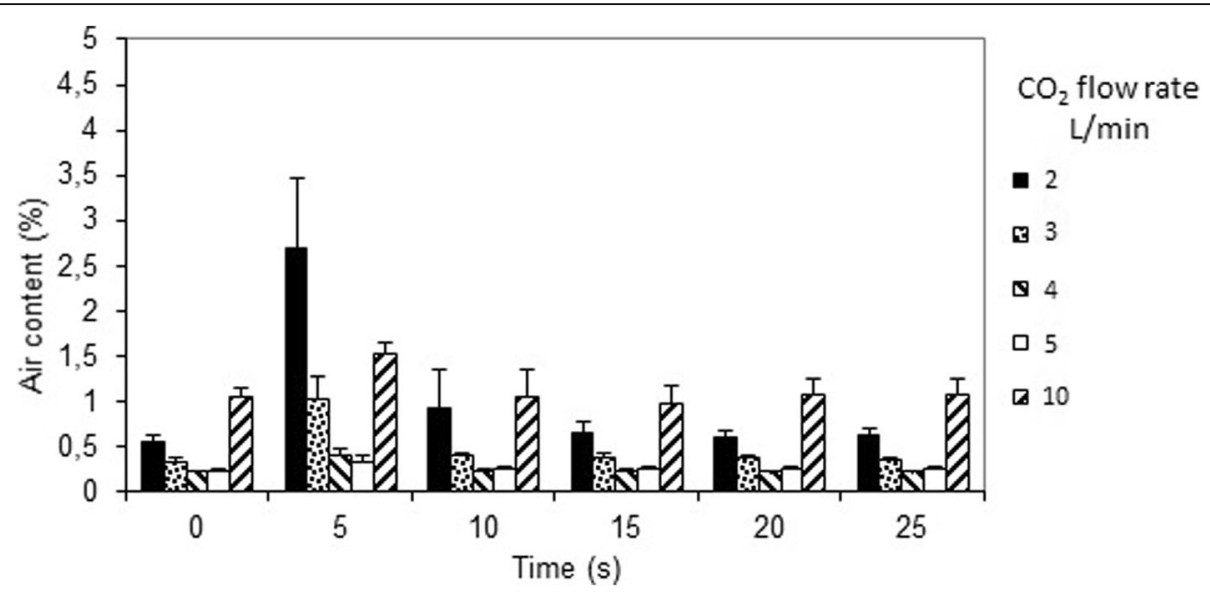

Fig. 5 Air content measured every five seconds, when using the new $\mathrm{CO}_{2}$ insufflation device and intermittent rough suction rate of $15 \mathrm{~L} / \mathrm{min}$ for two seconds from time zero. $\mathrm{CO}_{2}$ was insufflated at a flow rate of $2,3,4,5$, and $10 \mathrm{~L} / \mathrm{min}$, respectively

minimal invasive surgery. Earlier studies have also shown that efficient de-airing can only be accomplished by positioning the $\mathrm{CO}_{2}$ insufflation device inside the wound cavity and not next to its orifice [13]. Thus, there is a need for a new device that is small enough not to interfere with surgery and at the same time is large enough to enable efficient de-airing of a small open surgical wound. The new device was designed to meet these conditions and was in this study tested for its efficiency in comparison with an open-ended tube that is alternatively used for this purpose in minimal invasive cardiac surgery.

The mini-diffuser was evaluated in an experimental setup to enable us to vary several basic variables known to influence de-airing during surgery in an open wound, including geometry, flow rates, and a suction force from a suction device positioned in the wound cavity [14].
The size of the surgical wound model was based on measurements from the size of the partial sternotomy wound in adult patients undergoing minimal invasive aortic valve surgery. Efficient $\mathrm{CO}_{2}$ de-airing also presupposed continuous insufflation of the $\mathrm{CO}_{2}$ gas to prevent air from entering the open heart and vessels, since otherwise air trapped inside the heart and vessels cannot be removed. The $\mathrm{CO}_{2}$ flow rate was thus varied between a low rate of $2 \mathrm{~L} / \mathrm{min}$, which should be able to counteract against the strong force of diffusion from the ambient air, and a very high flow rate of $10 \mathrm{~L} / \mathrm{min}$, which is the recommended flow rate when applying a large diffuser device in adults undergoing open cardiac surgery via a complete sternotomy. Furthermore, the air content was measured not only at the base of the model but also close to its opening area, where the highest part of the ascending aorta is situated and where the diffusion

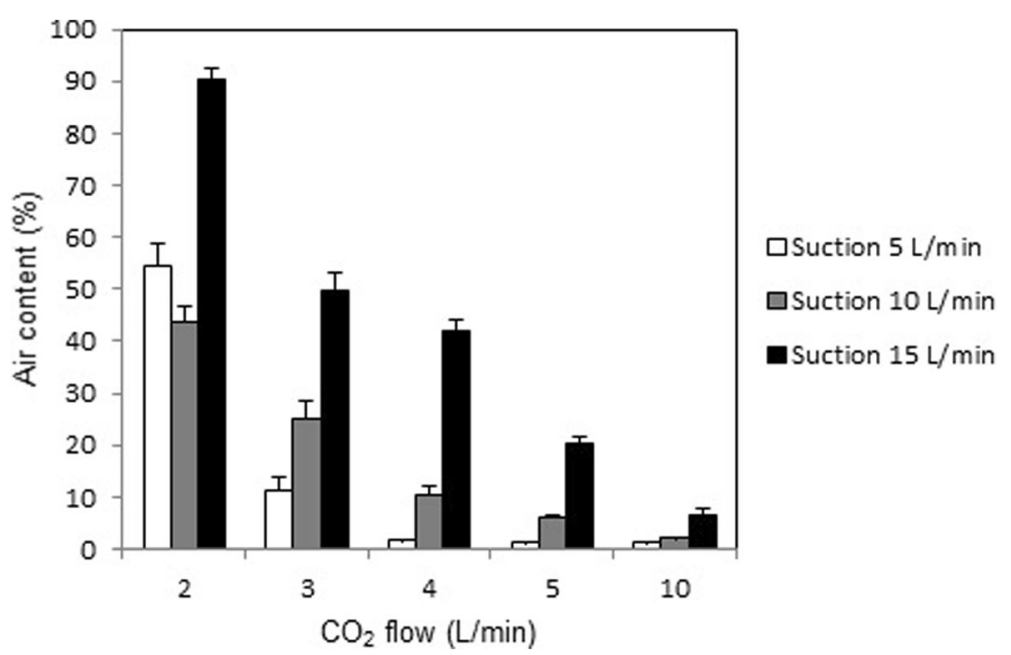

Fig. 6 Measured air content at steady state when using the new $\mathrm{CO}_{2}$ insufflation device and continuous rough suction force of 5 , 10 , and $15 \mathrm{~L} /$ min. $\mathrm{CO}_{2}$ was insufflated at a flow rate of $2,3,4,5$, and $10 \mathrm{~L} / \mathrm{min}$, respectively 
Table 1 Table summarizing results of the new device for 6 adult patients undergoing minimal invasive aortic valve replacement

\begin{tabular}{lllccc}
\hline & Mini-diffuser & $\begin{array}{l}\text { Postoperative stroke or } \\
\text { cognitive dysfunction }\end{array}$ & $\begin{array}{l}\text { Decrease in regional right or left } \\
\text { ventricular function after CPB }\end{array}$ & $\begin{array}{l}\text { Ventricular arrhythmias } \\
\text { after CPB }\end{array}$ \\
\hline $\mathrm{CO}_{2}$ flow rate & $5 \mathrm{~L} / \mathrm{min}$ & $8 \mathrm{~L} / \mathrm{min}$ & $0 / 6$ & $0 / 6$ & $0 / 6$ \\
Mean air content \% in surgical cavity & $<1 \%$ & $<1 \%$ & & & 0 \\
\hline
\end{tabular}

CPB Cardio-pulmonary bypass

towards ambient air will have its highest impact. Another factor that may influence the efficiency of de-airing is the intermittent use of suction devices during surgery. Thus, we positioned a surgical rough suction device inside the wound cavity model and applied a suction force of 5,10 , or $15 \mathrm{~L} / \mathrm{min}$ at the site of the artificial ascending aorta where a bleeding could be expected to occur.

Static de-airing with the open-ended tube resulted in a remaining air content that was above $10 \%$ at $2 \mathrm{~L} / \mathrm{min}$ and increased substantially with each increment in $\mathrm{CO}_{2}$ flow rate. These results can be explained by the turbulence caused by the high outflow velocity from the small orifice of the open-ended tube. In contrast, static de-airing of the minimal invasive wound cavity model with the new mini diffuser resulted in an air content that remained below $1 \%$ at $\mathrm{CO}_{2}$ flow rates between 2 and 5 $\mathrm{L} / \mathrm{min}$, and below $2 \%$ at a $\mathrm{CO}_{2}$ flow rate of $10 \mathrm{~L} / \mathrm{min}$ (Fig. 2). With the new mini-diffuser, the flow rates of 3$5 \mathrm{~L} / \mathrm{min}$ has the advantage of minimizing the remaining air content, whereas the highest tested flow rate of $10 \mathrm{~L} /$ min will minimize the dynamic influence of surgical maneuvers and suction devices on de-airing.

Two types of suction devices are usually used in cardiac surgery. A low force suction device is often applied at the base of the surgical wound cavity for continuous drainage of blood at a suction rate of 0.25 to $1 \mathrm{~L} / \mathrm{min}$, which will only interfere with de-airing if it is close to the $\mathrm{CO}_{2}$ insufflation rate. In contrast, rough suction devices with a high suction rate used intermittently for evacuation of local blood from the operating area enable optimal surgical exposure and visualization without interfering with $\mathrm{CO}_{2}$ de-airing during conventional cardiac surgery with complete sternotomy [14].

When a rough suction force of $10 \mathrm{~L} / \mathrm{min}$ was applied intermittently, the measured air content in the wound cavity model was kept below $1 \%$ at $\mathrm{CO}_{2}$ flows between 3 and $5 \mathrm{~L} / \mathrm{min}$, whereas the air content rose above $2.5 \%$ at a $\mathrm{CO}_{2}$ flow rate of $2 \mathrm{~L} / \mathrm{min}$. A further increase of an intermittent suction force to $15 \mathrm{~L} / \mathrm{min}$ would necessitate a higher insufflation rate of $\mathrm{CO}_{2}$. Indeed, when applying an intermittent suction rate of $15 \mathrm{~L} / \mathrm{min}$, the air content was kept at $<1 \%$ with $\mathrm{CO}_{2}$ flow rates of 4 to $5 \mathrm{~L} / \mathrm{min}$, and slightly above $1 \%$ at a $\mathrm{CO}_{2}$ flow rate of $10 \mathrm{~L} / \mathrm{min}$.

In comparison, when a rough suction rate of $15 \mathrm{~L} / \mathrm{min}$ was applied continuously in the wound cavity model at $\mathrm{CO}_{2}$ flow rates of 2 to $5 \mathrm{l}$, the air content was above
$20 \%$. With a $\mathrm{CO}_{2}$ flow rate of $10 \mathrm{~L} / \mathrm{min}$ the air content decreased to $<7 \%$. Accordingly, when using rough suction force of $10 \mathrm{~L} / \mathrm{min}$ continuously in the minimal invasive wound cavity model, the air content was $>20 \%$ with a $\mathrm{CO}_{2}$ flow rate of 2 and $3 \mathrm{~L} / \mathrm{min}$, whereas with a with a $\mathrm{CO}_{2}$ flow rate of 4,5 , and $10 \mathrm{~L} / \mathrm{min}$ the air content was $\leq 10 \%$. However, to avoid air trapping the use of continuous suction should be avoided, especially during cannulation and opening of the large vessels and heart chambers. The use of continuous suction in a situation of profuse bleeding will usually be performed with coronary suction devise at a much lower suction force, and will thus not affect de-airing.

The new mini diffuser was then tested clinically during minimal invasive aortic surgery and was found to de-air the open surgical wound cavity efficiently, i.e. less than $1 \%$ remaining air, at a continuous flow rate of 5 and $8 \mathrm{~L} /$ min, respectively. Thus, one could use the higher flow rate of $8 \mathrm{~L} / \mathrm{min}$ if one expects to use a rough suction device frequently or for longer durations.

There are some limitations to the study that should be acknowledged. We performed most of the measurements using a model instead of testing the new device at different measuring points, flow and suction rates in a clinical setting. However, all these measurements would have been ethically questionable to perform in patients. Furthermore, we did not perform an evaluation of the possible impact on cognitive function by prevention of air embolism via continuous $\mathrm{CO}_{2}$ de-airing during minimal invasive aortic valve surgery. On the other hand, prevention of air embolism should be possible by efficient $\mathrm{CO}_{2}$ de-airing of the open surgical wound, and thus should prevent air from entering the open heart and great vessels.

In earlier clinical trial in patients undergoing open heart surgery through a full sternotomy [15] we randomized patients to insufflation of the open cardiothoracic cavity with $\mathrm{CO}_{2}$ via a standard gas diffuser, or not. Microemboli were ascertained by intraoperative transoesophageal echocardiography (TOE) and recorded on videotape from the moment that the aortic cross-clamp was released until $20 \mathrm{~min}$ after end of cardiopulmonary bypass (CPB). The surgeon performed standard de-airing manoeuvres without being aware of TOE findings. Postoperatively, a blinded assessor determined the maximal number of gas emboli during each consecutive minute in the left atrium, left ventricle, and ascending 
aorta. The median number of microemboli registered during the whole study period was 161 in the $\mathrm{CO}_{2}$ group versus 723 in the control group $(P<0.001)$. Corresponding numbers for the left atrium were 69 versus $340(\mathrm{P}<$ $0.001)$, left ventricle 68 versus $254(\mathrm{P}<0.001)$, and ascending aorta 56 versus $185(\mathrm{P}<0.001)$. In the $\mathrm{CO}_{2}$ group, the median number of detectable microemboli after $\mathrm{CPB}$ fell to zero $7 \mathrm{~min}$ after $\mathrm{CPB}$ versus $19 \mathrm{~min}$ in the control group $(\mathrm{P}<0.001)$. This study design allowed us to follow the movements of the microemboli over a period of time and they behaved according to a characteristic pattern. First, an early peak occurred just after release of the aortic cross-clamp. Most of the microemboli were then whirling around in the left ventricle and the left atrium and were not propagated forward, whereas only a small fraction appeared in the ascending aorta. A second peak arose when the beating heart was being filled and started to eject blood during weaning from CPB. During this phase, most microemboli originated from the pulmonary veins. They first appeared as floating strings of pearls at the roof of the left atrium, they were then propagated forward to the left ventricle and finally ejected into the ascending aorta. Despite thorough surgical de-airing, new microemboli continued to pop up in the left atrium even up to $20 \mathrm{~min}$ after end of CPB. The second peak agrees with our earlier transcranial Doppler study during open-heart surgery, in which we found that most microemboli reached the brain during and after weaning from $\mathrm{CPB}$ [8]. This is the critical moment, as it is during weaning from $\mathrm{CPB}$ that the heart starts ejecting microemboli to the brain. Thus, it is then that the difference in the number of microemboli between the $\mathrm{CO}_{2}$-treated patients and the controls comes to the fore [8]. Furthermore, it should be kept in mind that in the $\mathrm{CO}_{2}$-treated patients, the microemboli were not only fewer in number but also differed from those in the untreated group as to their composition [15]. They consisted of $\mathrm{CO}_{2}$ and not of air.

\section{Conclusion}

The mini diffuser was effective for carbon dioxide de-airing, i.e. $<1 \%$ remaining air (Table 2 ), of a minimal invasive cardiothoracic wound cavity model with and without intermittent rough suction as well as in patients undergoing minimal invasive aortic valve surgery.

Table 2 Table summarizing comparison between the experimental results of the new device to the control

\begin{tabular}{lccccc}
\hline Insufflation device & \multicolumn{2}{l}{$\begin{array}{l}\text { Open-ended tube } \\
\text { (1 mm inner diameter) }\end{array}$} & & \multicolumn{2}{c}{ Mini-diffuser } \\
\cline { 2 - 3 } \cline { 5 - 6 } $\mathrm{CO}_{2}$ flow rate & $5 \mathrm{~L} / \mathrm{min}$ & $10 \mathrm{~L} / \mathrm{min}$ & & $5 \mathrm{~L} / \mathrm{min}$ & $10 \mathrm{~L} / \mathrm{min}$ \\
\hline $\begin{array}{l}\text { Mean air content } \% \\
\text { in wound model }\end{array}$ & $43 \%$ & $49 \%$ & & $<1 \%$ & $<1 \%$ \\
\hline
\end{tabular}

\section{Abbreviations}

C: Celsius; $\mathrm{CO}_{2}$ : Carbon dioxide; L/min: Liters per minute; m: Meter; mbar: millibar; $\mathrm{mm}$ : millimeter; $\mathrm{mm}^{2}$ : square millimeter; $\mathrm{O}_{2}$ : Oxygen; PVC: Poly vinyl chloride

\section{Acknowledgements}

Not applicable.

Funding

The study is funded by grants from Karolinska Institutet.

Availability of data and materials

The datasets used are available from the corresponding author on reasonable request.

\section{Authors' contributions}

All authors have equally contributed to the design of the study, collection of data and writing of the manuscript. All authors read and approved the final manuscript.

\section{Ethics approval and consent to participate}

Ethical Approval is obtained from the Regional ethics comity of Stockholm 2015/323-32. Informed consent to participate in the study was given by the participating patients.

\section{Consent for publication}

Not applicable.

\section{Competing interests}

JvdL and PS are shareholders of the company that manufactures the minidiffuser and JvdL is a member of the company board.

\section{Publisher's Note}

Springer Nature remains neutral with regard to jurisdictional claims in published maps and institutional affiliations.

\section{Author details}

${ }^{1}$ Division of Perioperative Medicine and Intensive Care, Section Cardiothoracic Surgery and Anesthesiology, Karolinska University Hospital Solna, SE-17176 Stockholm, Sweden. ${ }^{2}$ Department of Molecular Medicine and Surgery, Karolinska Institutet, Stockholm, Sweden. ${ }^{3}$ Section of Cardiac Surgery, Karolinska University Hospital, Stockholm, Sweden.

Received: 16 October 2018 Accepted: 26 December 2018

Published online: 17 January 2019

\section{References}

1. Fries CC, Levowitz B, Adler S, Cook AW, Karlson KE, Dennis C. Experimental cerebral air embolism. Ann Surg. 1957;145:461-70.

2. Kunkler A, King H. Comparison of air, oxygen and carbon dioxide embolization. Ann Surg. 1959:149:95-9.

3. Eguchi S, Sakurai Y, Yamaguchi A. The use of carbon dioxide gas to prevent air embolism during open heart surgery. Acta Med Biol. 1963;11:1-13.

4. Goldfarb D, Bahnson HT. Early and late effects on the heart of small amounts of air in the coronary circulation. J Thorac Cardiovasc Surg. 1963; 46:368-78.

5. Spencer FC, Rossi NP, Yu S-C, Koepke JA. The significance of air embolism during cardiopulmonary bypass. J Thorac Cardiovasc Surg. 1965:49:615-34.

6. Hindman BJ, Dexter F, Subieta A, Smith T, Cutkomp J. Brain injury after cerebral arterial air embolism in the rabbit as determined by triphenyltetrazolium staining. Anesthesiology. 1999;90:1462-73.

7. Borger MA, Peniston CM, Weisel RD, Vasiliou M, Green RE, Feindel CM. Neuropsychologic impairment after coronary bypass surgery: effect of gaseous microemboli during perfusionist interventions. J Thorac Cardiovasc Surg. 2001;121:743-9.

8. van der Linden J, Casimir-Ahn H. When do cerebral emboli appear during open heart operations? A transcranial Doppler study. Ann Thorac Surg. 1991;51:237-41.

9. Tingleff J, Joyce FS, Pettersson G. Intraoperative echocardiographic study of air embolism during cardiac operations. Ann Thorac Surg. 1995;60:673-7. 
10. Ng SW, Rosen M. Carbon dioxide in the prevention of air embolism during open-heart surgery. Thorax. 1968;23:194-6.

11. Eguchi S, Bosher LH Jr. Myocardial dysfunction resulting from coronary air embolism. Surgery. 1962;51:103.

12. Moore RM, Braselton CW Jr. Injection of air and of carbon dioxide into a pulmonary vein. Ann Surg. 1940;112:212-8.

13. Persson $M$, Svenarud $P$, van der Linden J. What is the optimal device for carbon dioxide de-airing of the cardiothoracic wound and how should it be positioned? J Cardiothorac Vasc Anesth. 2004;18:180-4.

14. Svenarud $P$, Persson $M$, van der Linden J. Efficiency of a gas-diffuser and influence of suction in carbon dioxide de-airing of a cardiothoracic wound cavity model. J Cardiothorac Vasc Anesth. 2003;125(5):1043-9.

15. Svenarud $\mathrm{P}$, Persson $\mathrm{M}$, van der Linden J. Effect of $\mathrm{CO} 2$ insufflation on the number and behavior of air microemboli in open-heart surgery: a randomized clinical trial. Circulation. 2004:109(9):1127-32.

Ready to submit your research? Choose BMC and benefit from:

- fast, convenient online submission

- thorough peer review by experienced researchers in your field

- rapid publication on acceptance

- support for research data, including large and complex data types

- gold Open Access which fosters wider collaboration and increased citations

- maximum visibility for your research: over $100 \mathrm{M}$ website views per year

At BMC, research is always in progress.

Learn more biomedcentral.com/submissions 